\title{
Characterization of the retinal vasculature in fundus photos using the PanOptic iExaminer system
}

\author{
Huiling $\mathrm{Hu}^{1,2}$, Haicheng Wei ${ }^{3,4}$, Mingxia Xiao ${ }^{3,4}$, Liqiong Jiang ${ }^{1}$, Huijuan Wang ${ }^{2,5}$, Hong Jiang ${ }^{2,6}$,
} Tatjana Rundek ${ }^{6}$ and Jianhua Wang ${ }^{2^{*}}$

\begin{abstract}
Background: The goal was to characterize retinal vasculature by quantitative analysis of arteriole-to-venule (AN) ratio and vessel density in fundus photos taken with the PanOptic iExaminer System.

Methods: The PanOptic ophthalmoscope equipped with a smartphone was used to acquire fundus photos centered on the optic nerve head. Two fundus photos of a total of 19 eyes from 10 subjects were imaged. Retinal vessels were analyzed to obtain the AN ratio. In addition, the vessel tree was extracted using deep learning U-NET, and vessel density was processed by the percentage of pixels within vessels over the entire image.

Results: All images were successfully processed for the AN ratio and vessel density. There was no significant difference of averaged $\mathrm{A} N$ ratio between the first $(0.77 \pm 0.09)$ and second $(0.77 \pm 0.10)$ measurements $(P=0.53)$. There was no significant difference of averaged vessel density (\%) between the first $(6.11 \pm 1.39)$ and second $(6.12 \pm$ 1.40) measurements $(P=0.85)$.

Conclusions: Quantitative analysis of the retinal vasculature was feasible in fundus photos taken using the PanOptic ophthalmoscope. The device appears to provide sufficient image quality for analyzing AN ratio and vessel density with the benefit of portability, easy data transferring, and low cost of the device, which could be used for pre-clinical screening of systemic, cerebral and ocular diseases.
\end{abstract}

Keywords: Smartphone ophthalmoscope, Image analysis, Deep learning, Arteriovenous ratio, Vessel density, Retina

\section{Background}

The retina provides a direct, non-invasive, and easily accessible window for observing the microvascular system. The vasculature of the retina and brain are anatomically and physiologically similar [1]. Fundus photography is a useful tool to observe and monitor changes in the retinal vasculature. Large-scale epidemiology studies based on fundus photography reported that the changes of retinal

\footnotetext{
* Correspondence: jwang3@med.miami.edu

${ }^{2}$ Department of Ophthalmology, Bascom Palmer Eye Institute, University of Miami Miller School of Medicine, 1638 NW 10th Avenue, McKnight Building Room 202A, Miami, FL 33136, USA

Full list of author information is available at the end of the article
}

vessels are associated with the risk of retinal and systemic diseases, including diabetic retinopathy [2], stroke [3], cardiovascular mortality [4] and dementia [5].

While the traditional fundus camera offers goodquality images for analysis of large retinal vessels, these fundus camera systems are based in hospitals and research facilities. The office-based systems require skillful technicians and are limited to the subjectivity of the clinician's interpretation. These systems are also bulky and costly, which limits their use in community screening efforts, especially in remote areas [6]. Two recent remarkable breakthroughs are improvements in teleophthalmology and smartphone adapted devices. With 
the advantage of easy image capturing, easy data transferring, and low cost, the PanOptic ophthalmoscope adapted with a smartphone and data acquisition application (iExaminer) may provide an ideal solution for preclinical disease screening [7-9]. The PanOptic ophthalmoscope system has been used in some previous studies. However, none of these previous studies quantified retinal vasculature, which renders whether the system can be used to characterize retinal vasculature. The goal of the present study was to characterize retinal vasculature by quantitative analysis of arteriole-to-venule (A/V) ratio and vessel density in smartphone-acquired fundus photographs using the PanOptic iExaminer System.

\section{Methods}

\section{Subject selection}

This study was approved by the Institutional Review Board (IRB) of the University of Miami (ID: 20070492), and all study subjects were treated according to the tenets of the Declaration of Helsinki. A signed written informed consent was obtained from each subject. Ten subjects were recruited at the Bascom Palmer Eye Institute. A total of 19 eyes were imaged. One study subject agreed to have one eye dilated for the present study. The following exclusion criteria were used: shallow anterior chamber, ocular surgery history, refractive errors more than \pm 6.0 diopters, or any systemic inflammatory or infectious diseases.

\section{Image capture}

PanOptic ophthalmoscope (WelchAllyn, Skaneateles Falls, NY) was mounted on a slit-lamp base to facilitate the alignment of the system with the eye (Fig. 1). An external fixation target, placed in front of the contralateral eye, was also provided. The PanOptic ophthalmoscope was adapted to the iExaminer adapter (WelchAllyn, Skaneateles Falls, NY). Fundus images were captured by the iExaminer Pro application with the iPhone $6 \mathrm{~s}$. A short video clip was recorded during acquisition; then, the five best images were manually selected based on the focus of vasculature and optimal visualization (Fig. 1). For the field of view calibration, a Zeiss field of view calibration tool (S/N4007) was placed in front of the ophthalmoscope under room light (Fig. 1). The field of view was calibrated to $7.0 \mathrm{~mm} \times 7.0 \mathrm{~mm}$ with the emitted light on. Each eye was dilated with topical tropicamide $1.0 \%$. During imaging in a dark test room, the subject was seated, and the chin rested on the chinrest while looking at the fixation target.

\section{A/ $\mathbf{V}$ ratio analysis}

The exported raw image was 1024 (vertical) $\times 720$ (horizontal) pixels. To make the image conform to a square
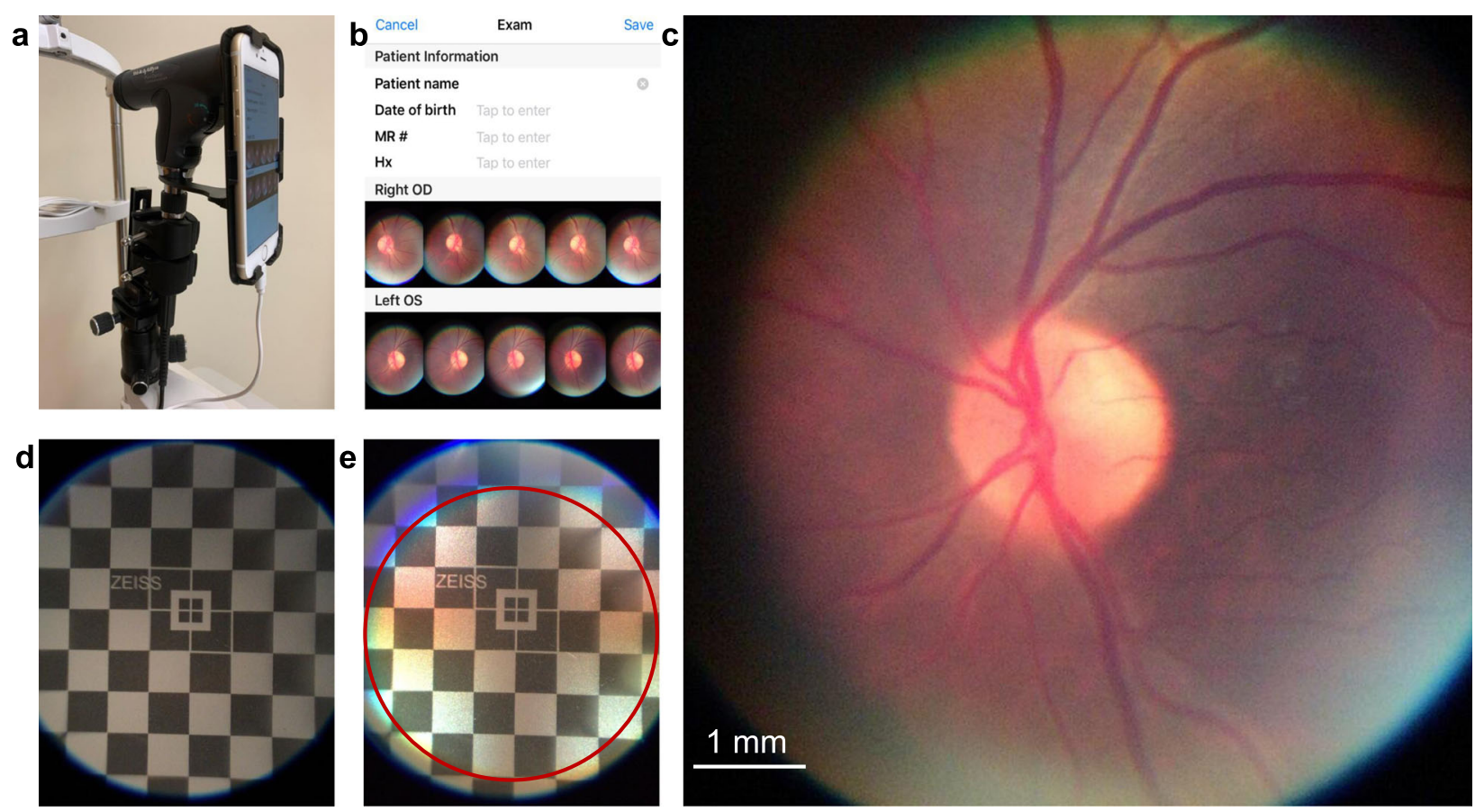

Fig. 1 PanOptic iExaminer System and field of view calibration. a PanOptic ophthalmoscope adapted with a smartphone (iPhone $6 \mathrm{~s}$ ) was mounted on a slit lamp base with the chinrest. $\mathbf{b}$ iExaminer software was used for image acquisition. $\mathbf{c}$ A representative fundus photo was captured using the system. $\mathbf{d}$ The field of view (without internal illumination) was tested using the Zeiss field of view calibration tool placed in front of the PanOptic ophthalmoscope under room light. e The field of view was calibrated as $7.0 \mathrm{~mm} \times 7.0 \mathrm{~mm}$ with the emitted light on 
ratio, the black portions on the top and bottom of the image were removed, and the raw image was trimmed to $720 \times 720$ pixels with a field of view of $7.0 \times 7.0 \mathrm{~mm}$ (Fig. 2). The measurement area for arteriole and venule was done within 0.5 to 1 disc diameter from the edge of the disc margin, as done in previous studies [10, 11]. The selected parallel arteriole and venule diameters were measured using the straight-line measurement tool of ImageJ. Five non-overlapping measurements for each vessel were made (Fig. 2). The diameters were then averaged, and the arteriole to venule ratio was calculated. Two photographs with the best focusing and centration of the optic nerve head of each eye were selected and calculated. The measurement for the $\mathrm{A} / \mathrm{V}$ ratio was performed by two researchers.

\section{Vessel extraction using deep learning U-NET and density} analysis of retinal vessels

We developed the image processing codes in the MATL AB (MathWorks, Natick, MA) for image conversion and filtering. We also developed U-Net image segmentation in Python (ver. 3.6.5). The photograph was converted into a square with a resolution of $565 \times 565$ pixels (Fig. 3 ) and then transformed into the grayscale format using Gray $=$ MAX Contrast (R, G, B). Although the green channel is commonly used to convert RGB images to grayscale, we used all channels to convert the RGB images so that they would contain more of the red color in these fundus photos to preserve more details of the vessels. The weight of each channel was obtained from the training set (DRIVE), and the setting was red $\times 0.299+$ green $\times 0.587+$ blue $\times 0.114$. The image was then processed by contrast enhancement using contrast limited adaptive histogram equalization (CLAHE). We used the function of adapthisteq with NumTiles (25, 25), Cliplimit (0.01). Other parameters were set to default. The image was then processed using the function of imadjust (stretchlim, output $=0$ to 1 , gamma $=0.6$ ). The image was further processed by the linear filter and edge enhancement to enhance the vessel border (Fig. 3) [12].

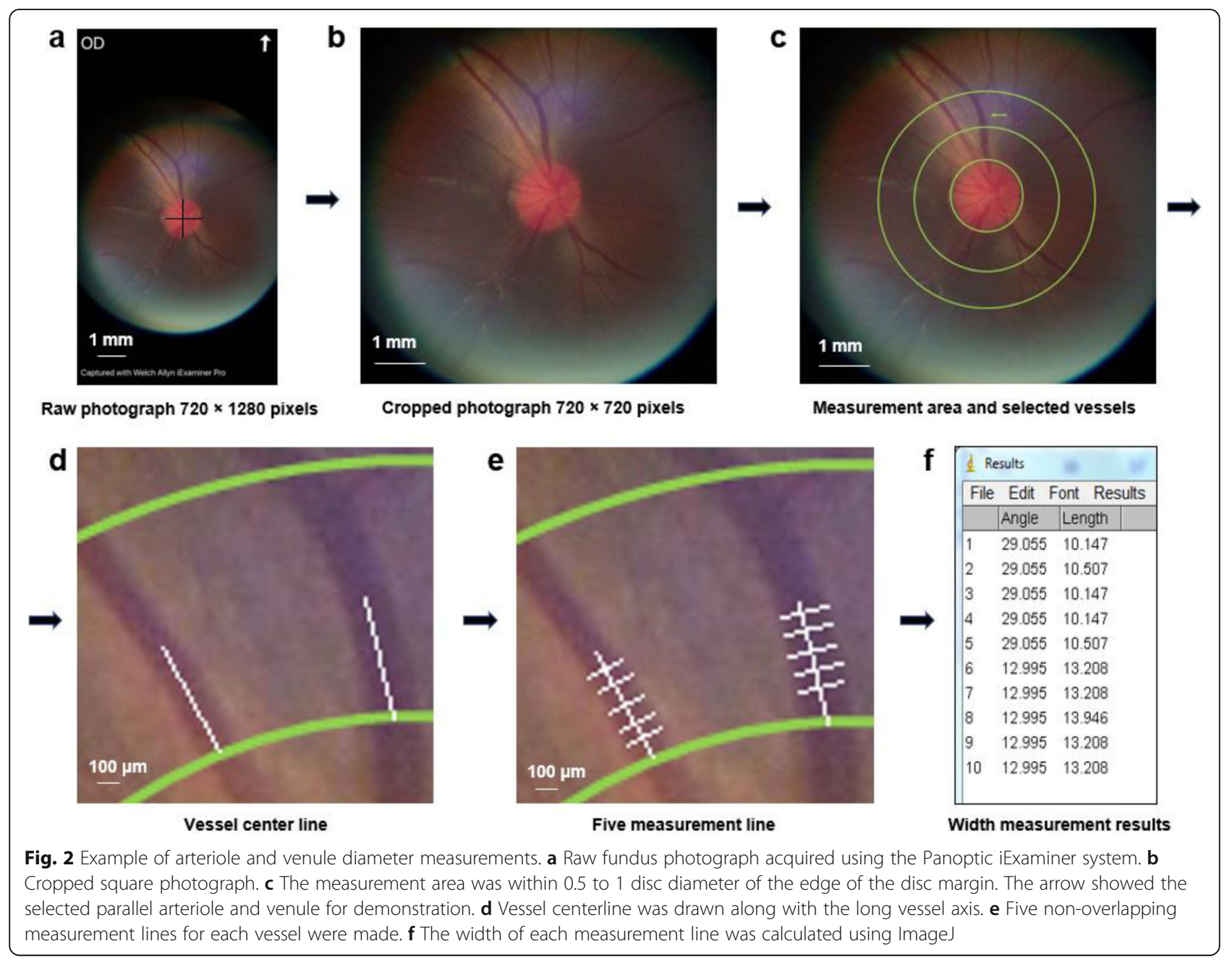




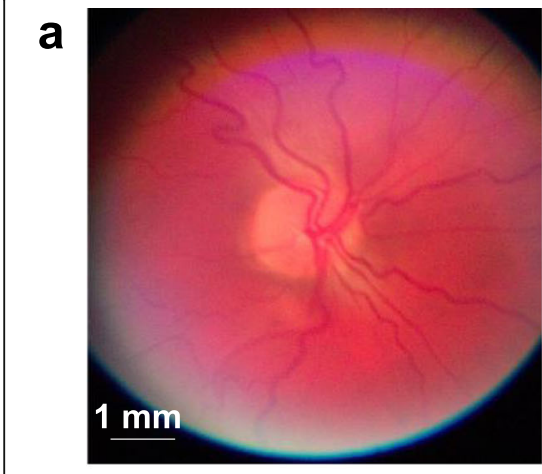

Adjusted photograph $565 \times 565$ pixels

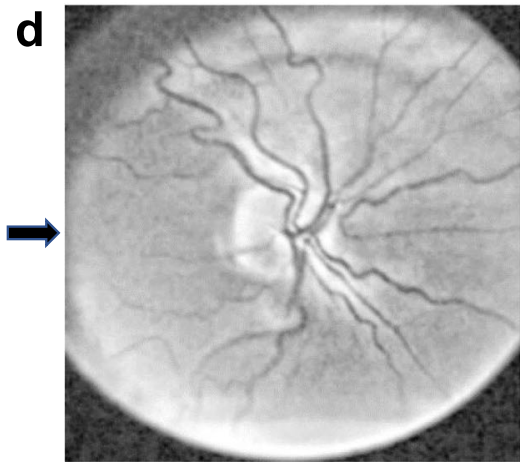

Linear filter and edge enhancement

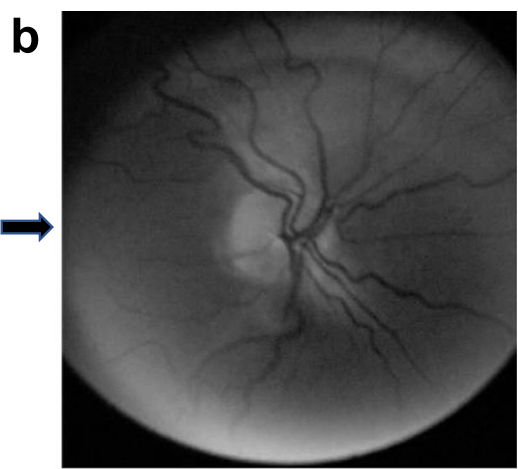

Gray scale conversion

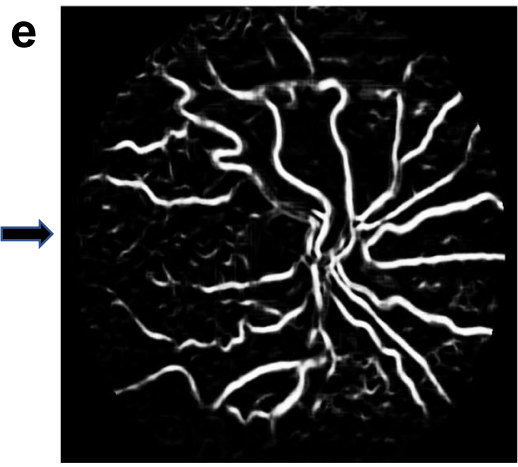

Vessel extraction using U-Net

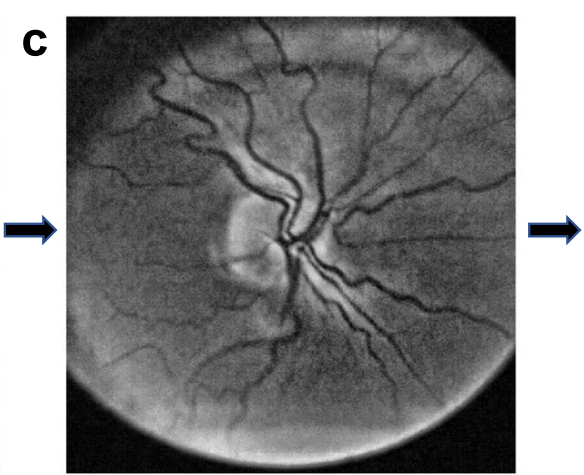

Contrast limited adaptive histogram equalization

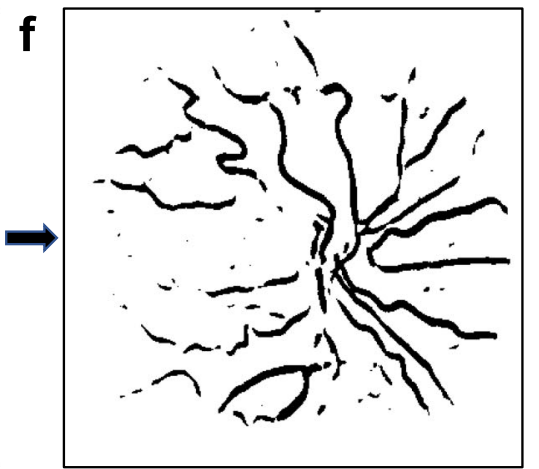

Binary conversion

Fig. 3 Example of retinal vessel density analysis. a Cropped square photograph. b Grayscale conversion using Gray= MAX Contrast. c Contrast enhancement using contrast limited adaptive histogram equalization. $\mathbf{d}$ Vessel border enhancement using the linear filter and edge enhancement. e Vessel extraction using U-Net. f Vessel binary conversion using ImageJ

We used the MATLAB function of imfilter [parameters: $\mathrm{w}=$ fspecial $\quad$ (average $=11$, boundary options $=$ replicate, others $=$ default $]$ to remove the artifact of the image edge, which was enhanced during the image contrast enhancement. This process will not affect the extraction of the vessels. In recent years, semantic segmentation methods have been used to segment the vessels from fundus photos, using deep learning approaches $[13,14]$. One of the most representative networks is U-Net (convolutional neural network), which was developed for the biomedical imaging segment. This approach often uses the handlabeled picture as the ground truth for the learning model. The U-NET deep learning method has been well described in previous studies [13-16]. In the present study, the U-NET structure based on the fully convolutional neural network [15] was developed and then used to enhance the contrast of vessels. After that, blood vessels were extracted (Fig. 3). The Ushaped network used 23 convolutional layers. The public datasets of digital retinal images for vessel extraction (Drive: https://www.isi.uu.nl/Research/Databases/DRIVE/) [13, 14, 17] were used as the training data. There were a total of 40 source images $(565 \times$ 584 pixels), which were used as training images. The random image patches were generated from the training image data and patched into the training image dataset [14]. A total of 38 blood vessel images were processed [13, 14]. The images were then converted to binary for vessel density analysis using ImageJ (Fig. 3 ). Vessel density was defined as the percentage of pixels within the vessels over the entire image.

\section{Statistical analysis}

All values are expressed as mean \pm standard deviation. Significance was assessed with the Student's t-test for two variable comparisons using SPSS Statistics package (ver. 25, IBM Corp., Armonk, NY, USA). Pearson's regression was used to determine the relationships among parameters. The Bland-Altman plot was constructed between the two measurements to determine the 95\% limit of agreement, which was calculated as $1.96 \times$ (the standard deviation of the difference between repeated measurements). $P<0.05$ was considered statistically significant. 
Table 1 Demographic information

\begin{tabular}{lll}
\hline & Mean \pm SD & Range \\
\hline Age (years) & $49.5 \pm 13.7$ & $30-71$ \\
SBP (mmHg) & $121.8 \pm 19.5$ & $101-162$ \\
DBP (mmHg) & $77.5 \pm 8.8$ & $62-88$ \\
HR (beats/min) & $75.2 \pm 11.0$ & $60-94$ \\
\hline
\end{tabular}

$S B P=$ systolic blood pressures, $D B P=$ diastolic blood pressures, $H R=$ heart rate

\section{Results}

\section{Subject characteristics}

Demographic information is shown in Table 1. Three participants were male, seven were female. Three study participants were healthy subjects, four had a history of diabetes mellitus (DM), and three had a history of multiple sclerosis (MS). In a total of 19 eyes, 10 eyes were right eyes, and 9 eyes were left eyes.

\section{A/V ratio}

The A/V analysis was successfully processed in all subjects of each group (Fig. 4). There was no significant difference of averaged $\mathrm{A} / \mathrm{V}$ ratio between the first $(0.77 \pm$

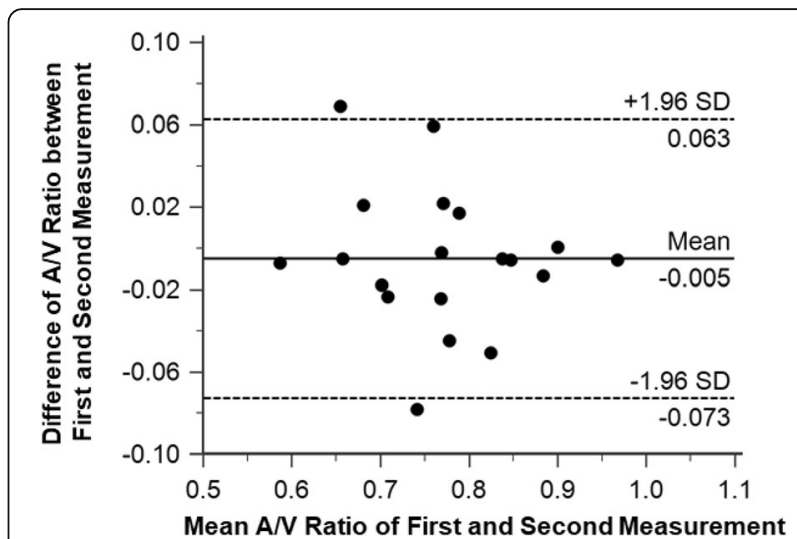

Fig. 5 AN ratio calculation of first and second measurements. Bland-Altman plot of differences in the first measurement vs. the second measurement

$0.09)$ and second $(0.77 \pm 0.10)$ measurements $(P=0.53)$ (Fig. 5). The A/V ratio of the first measurement ranged from 0.58 to 0.96 , while it ranged from 0.59 to 0.97 in the second measurement. Two measurements were significantly correlated $(r=0.94, P<0.001)$ (Fig. 5). Bland-

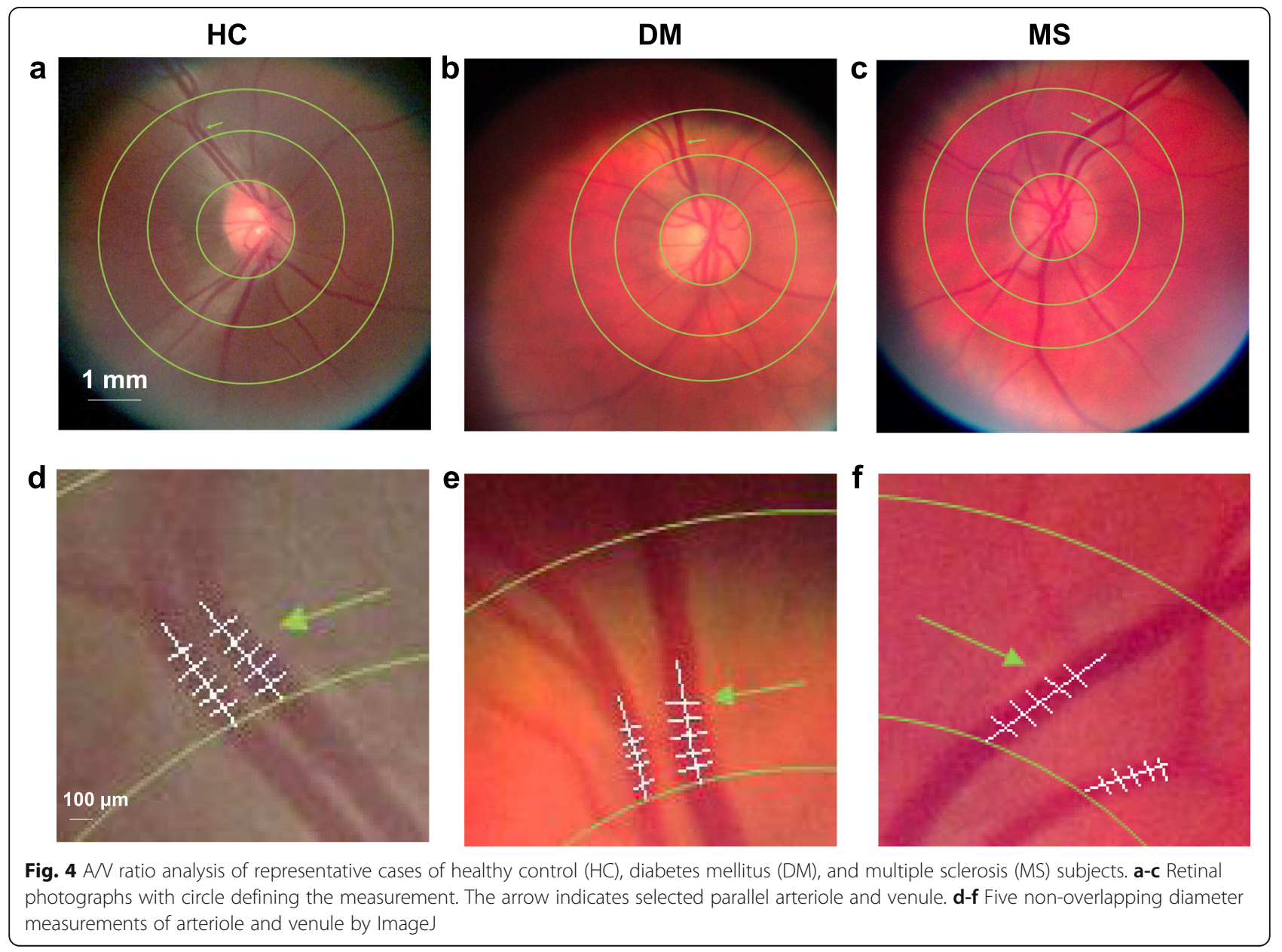


Altman plot for the two measurements showed a bias of -0.005 with upper and lower confidence intervals of 0.063 and -0.073 , respectively.

\section{Vessel density}

Vessels were extracted from the fundus photos of subjects for analysis of vessel density (Fig. 6). There was no significant difference of averaged vessel density (\%) between the first $(6.11 \pm 1.39)$ and second $(6.12 \pm 1.40)$ measurements $(P=0.85)$ (Fig. 7). In the first measurement, vessel density ranged from 3.64 to 8.42 , while it ranged from 3.63 to 8.30 in the second measurement. The two measurements were significantly correlated $(r=$ $0.97, P<0.001)$. Bland-Altman plot for the two measurements showed no bias with upper and lower confidence intervals of 0.60 and -0.63 , respectively.

\section{Discussion}

This study was to quantitatively analyze fundus photos for characterizing retinal vasculature by calculating the $\mathrm{A} / \mathrm{V}$ ratio and vessel density in fundus photos taken using the PanOptic iExaminer system. This study

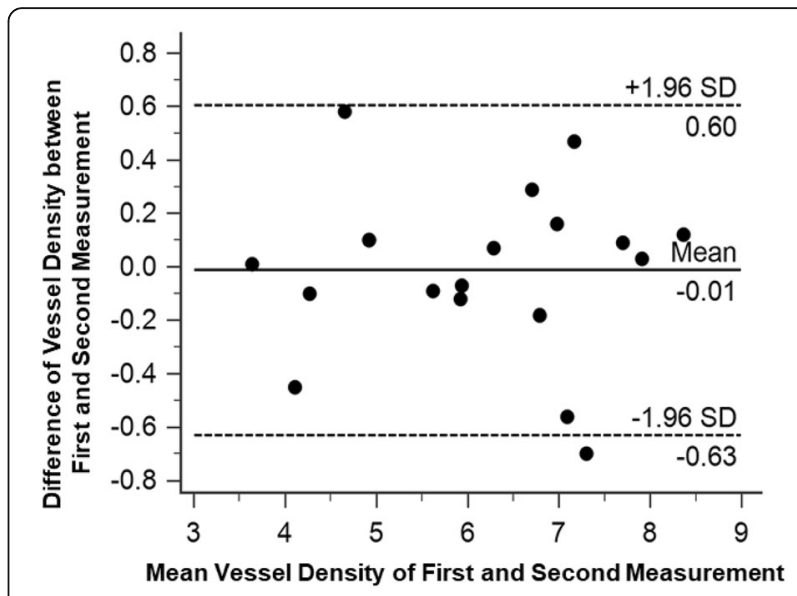

Fig. 7 Vessel density analysis of first and second measurements. Bland-Altman plot of differences in the first measurement vs. the second measurement

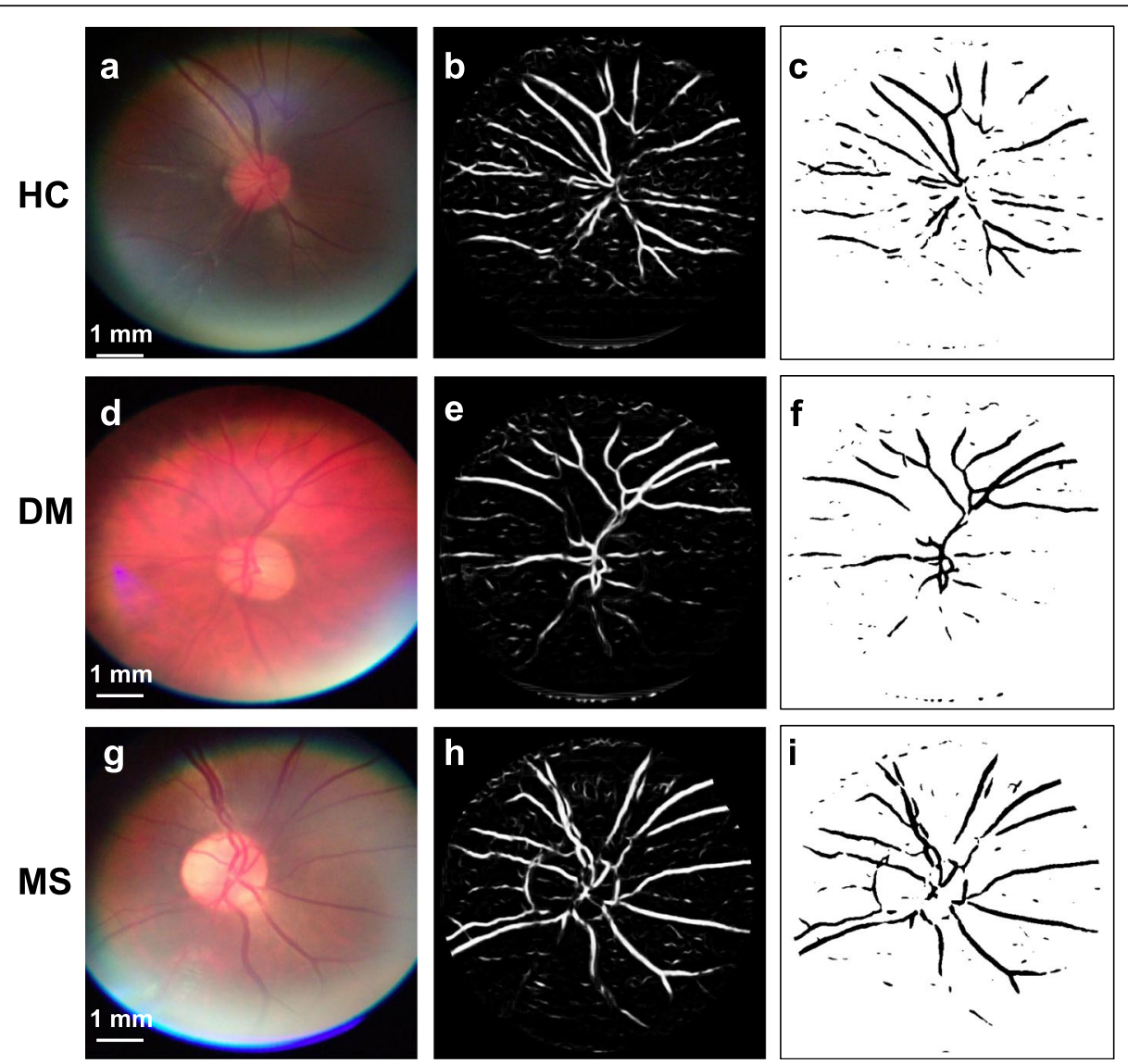

Fig. 6 Vessel density analysis of representative cases of healthy control (HC), diabetes mellitus (DM), and multiple sclerosis (MS) subjects. a, d, $\mathbf{g}$ Adjusted square photographs. b, e, h Vessel extraction images. $\mathbf{c}, \mathbf{f}$, i Binary images 
provides evidence that fundus photos with sufficient quality for analysis of $\mathrm{A} / \mathrm{V}$ ratio and vessel density, can be acquired using the portable PanOptic system for image analysis. The acquisition appeared to be facilitated by the modifications used in the present study. First, the ophthalmoscope was stabilized by the use of the slit-lamp base, which also made it easy to align with the eye. Second, the patient's head was stabilized by resting on the chinrest. Third, the fixation target facilitated the gaze direction for imaging. Fourth, pupil dilation also helped in image acquisition. It may be worth noting that while these modifications may not alter the portability and data transfer, the slit-lamp base with the chinrest can be easily transported with the portable ophthalmoscope. The inconvenience of the use of the slit-lamp base may not outweigh the gain of easy acquisition of high-quality images for quantitative analysis. It is also worth noting that some of the inexpensive handheld fundus cameras are also available, although some of these cameras do not use smartphones $[18,19]$. Based on the outcomes in the present study and previous studies [20], the PanOptic system could potentially be used for pre-screening in remote communities. It would be recommended that fundus photos may be analyzed using analysis software installed in the smartphone [20] or in fundus photo reading centers or research labs.

Previous studies (Table 2) demonstrated the usefulness of the PanOptic ophthalmoscope, while the present study provided an alternative solution to use the device with the add-on translator and chinrest. The PanOptic ophthalmoscope was used qualitatively for patients' fundus imaging in the emergency room [23] and optic disc assessment [24], for diabetic retinopathy screening [7, 9] and medical students ophthalmoscopy skills assessment [8]. There are some studies using the PanOptic device, quantitatively analyzing the vessel diameter in the retina [20] and anterior lens capsule vascularity only [22]. In addition, vessel segmentation and analysis based on fundus photos taken with the PanOptic ophthalmoscope were also done in previous studies [20,21]. Xu et al. did not analyze the $\mathrm{A} / \mathrm{V}$ ratio and vessel density [20, 21], which are critical to the clinical applications of the PanOptic ophthalmoscope equipped with a smartphone. In addition, $\mathrm{Xu}$ et al. did not analyze the repeatability of these important measurements (i.e., A/V ratio and vessel density) [20, 21]. Our work focused on the characterization of retinal vasculature by quantitatively

Table 2 Summary of PanOptic ophthalmoscopy studies

\begin{tabular}{|c|c|c|c|c|c|c|c|c|}
\hline Authors & Subjects & $\begin{array}{l}\text { Subjects } \\
\text { No. }\end{array}$ & Focus Area & $\begin{array}{l}\text { Pupil } \\
\text { Dilation }\end{array}$ & Smartphone & App & Mounted & Main outcome \\
\hline Xu et al. 2016 [20] & Normal & 10 & Retina & $\begin{array}{l}\text { Not } \\
\text { mentioned }\end{array}$ & Android & $\begin{array}{l}\text { iExaminer and } \\
\text { Android app }\end{array}$ & No & $\begin{array}{l}\text { Segment retinal vessels, } \\
\text { analyze vessel width, and } \\
\text { store or uplink results }\end{array}$ \\
\hline Xu et al. 2018 [21] & Normal & 10 & Retina & $\begin{array}{l}\text { Not } \\
\text { mentioned }\end{array}$ & $\begin{array}{l}\text { Not } \\
\text { mentioned }\end{array}$ & $\begin{array}{l}\text { Not } \\
\text { mentioned }\end{array}$ & $\begin{array}{l}\text { Not } \\
\text { mentioned }\end{array}$ & $\begin{array}{l}\text { Segment retinal arterioles } \\
\text { and venules }\end{array}$ \\
\hline Patel et al. 2019 [22] & $\begin{array}{l}\text { Preterm } \\
\text { infants }\end{array}$ & 24 & $\begin{array}{l}\text { Anterior lens } \\
\text { capsule } \\
\text { vascularity }\end{array}$ & No & $\begin{array}{l}\text { iPhone } 4 \\
\& 6 s\end{array}$ & MoviePro & Ring stand & $\begin{array}{l}\text { Quantitative analysis for } \\
\text { gestational age estimate }\end{array}$ \\
\hline Day, et al. 2017 [23] & $\begin{array}{l}\text { Pediatric } \\
\text { emergency } \\
\text { patients }\end{array}$ & 184 & Retina & No & $\begin{array}{l}\text { Not } \\
\text { mentioned }\end{array}$ & iExaminer & $\begin{array}{l}\text { Not } \\
\text { mentioned }\end{array}$ & $\begin{array}{l}\text { Feasibility of fundus } \\
\text { photography in pediatric } \\
\text { patients }\end{array}$ \\
\hline $\begin{array}{l}\text { Petrushkin et al. } 2012 \\
{[24]}\end{array}$ & $\begin{array}{l}\text { Emergency } \\
\text { patients }\end{array}$ & 36 & Optic disc & No & $\begin{array}{l}\text { No } \\
\text { photography }\end{array}$ & No & No & $\begin{array}{l}\text { More sensitive and specific } \\
\text { than the direct } \\
\text { ophthalmoscope }\end{array}$ \\
\hline Tan et al. 2010 [9] & $\begin{array}{l}\text { Diabetes } \\
\text { mellitus }\end{array}$ & 200 & Retina & Yes & $\begin{array}{l}\text { No } \\
\text { photography }\end{array}$ & No & No & $\begin{array}{l}\text { Not superior to direct } \\
\text { ophthalmoscope for } \\
\text { retinopathy }\end{array}$ \\
\hline Gill et al. 2004 [7] & $\begin{array}{l}\text { Diabetes } \\
\text { mellitus }\end{array}$ & 28 & Retina & No & $\begin{array}{l}\text { No } \\
\text { photography }\end{array}$ & No & No & $\begin{array}{l}\text { Fairly accurate in screening } \\
\text { diabetic retinopathy }\end{array}$ \\
\hline $\begin{array}{l}\text { McComiskie et al. } 2004 \\
\text { [8] }\end{array}$ & $\begin{array}{l}\text { Healthy } \\
\text { volunteers }\end{array}$ & 140 & Optic disc & $\begin{array}{l}\text { No } 75 \\
\text { Yes } 65\end{array}$ & $\begin{array}{l}\text { No } \\
\text { photography }\end{array}$ & No & No & $\begin{array}{l}\text { Easier to use, with the } \\
\text { accuracy of rating the cup } \\
\text { to disc ratio }\end{array}$ \\
\hline Desai et al. 2018 [25] & Neonates & 124 & $\begin{array}{l}\text { Anterior lens } \\
\text { capsule } \\
\text { vasculature }\end{array}$ & No & $\begin{array}{l}\text { iPhone } 6 \\
\text { Plus }\end{array}$ & iExaminer & No & Gestational age estimation \\
\hline Lee et al. 2020 [26] & $\begin{array}{l}\text { Healthy } \\
\text { volunteers }\end{array}$ & $\begin{array}{l}\text { Not } \\
\text { mentioned }\end{array}$ & $\begin{array}{l}\text { Optic nerve } \\
\text { head }\end{array}$ & No & $\begin{array}{l}\text { No } \\
\text { photography }\end{array}$ & No & No & $\begin{array}{l}\text { Ophthalmology clinical } \\
\text { training }\end{array}$ \\
\hline Besenczi et al. 2015 [27] & Normal & 16 & Retina & $\begin{array}{l}\text { Not } \\
\text { mentioned }\end{array}$ & iPhone 4/4S & iExaminer & No & $\begin{array}{l}\text { Automatic optic disc and } \\
\text { optic cup detection }\end{array}$ \\
\hline
\end{tabular}


analyzing $\mathrm{A} / \mathrm{V}$ and vessel density, which provides insightful information on the repeatability before testing whether the system can be used for clinical diagnosis. Although these previous studies [20,21] and the present study applied a similar methodology to extract the vessel information, this study provides additional information to the feasibility and repeatability of measuring $\mathrm{A} / \mathrm{V}$ ratio and vessel density. In addition, the alternative solution by adding the slit-lamp base may facilitate translating the portable ophthalmoscope equipped with the smartphone, such as the PanOptic device. However, more work needs to be done to test whether the portable ophthalmoscope equipped with the smartphone can differentiate diseased populations from the normal population.

Compared to images captured by traditional fundus cameras and Ultra-wide field scanning laser ophthalmoscopy (SLO), the resolution $(1280 \times 720$ pixels in video recording) of PanOptic fundus images is not high due to the settings in the iExaminer software for video recording. However, there are some advantages to making it a practical instrument for retina blood vessel analysis of disease screening (Table 3), which are its portability, low cost, smartphone adaptability, and easy data transferring. Traditional fundus camera offers good-quality images but is bulky, office-based, and technician dependent, which limits its use as a community screening tool, especially in remote areas. SLO, with a $180-200^{\circ}$ field of view, offers faster and easier image acquisition without pupil dilation when compared to traditional fundus cameras [28]. It is ideal for a hospital-based study. However, SLO is costly, which may reduce its availability for disease screening. In our future study, we will compare the retinal vascular network analysis results of the PanOptic iExaminer system with those of traditional fundus cameras and SLO.

The A/V ratio acquired using the PanOptic iExaminer system appeared within the range of those found at using the traditional fundus camera of previous large sample studies $[10,29,30]$. The good repeatability of this analysis indicated its feasibility using the analysis method of McClelland et al. [31] although in this study, the A/V ratio's correlation to other disease conditions was not analyzed as the focus of this paper was a feasibility test. Other studies already reported that the $\mathrm{A} / \mathrm{V}$ ratio of the retina is a widely used parameter in the assessment of different ocular and systemic vascular diseases, such as open-angle glaucoma [32], incident stroke [32], coronary heart disease [33] and dementia [34].

There were several limitations to this study. First, the aim of this study was to characterize retinal vasculature using the commercially available ophthalmoscope equipped with a smartphone by reporting the feasibility and repeatability of the measurements. Although this study provided an alternative solution for resourcelimited regions and countries, there are low-cost portable handheld fundus cameras such as the portable handheld camera with a retinal model (Pictor, Volk Optical, Inc., Mentor, OH, USA) [18, 35]. The camera could perform a similar task for pre-screening [18, 35]. Therefore, more work will need to be done to test whether the portable ophthalmoscope equipped with the smartphone, such as the PanOptic ophthalmoscopy, can be used to screen for retinal diseases. Second, although we aimed for the feasibility of analysis, the sample size was still small. We could not compare the differences among groups. Larger sample size and case-control studies are needed to further verify further whether the described method could differentiate vasculature alterations in the pathologic retina. Third, adding the slit-lamp translator and chin-and-head rest as an alternative add-on of the PanOptic ophthalmoscope will increase the cost, which amounts to an entry-level retinal camera. Nevertheless, our study provided an alternative solution to use the PanOptic ophthalmoscope with the translator and chinrest. Fourth, we did not compare the benefit of the smartphone to other portable fundus cameras without smartphones. While different approaches using the smartphone on the handheld fundus camera or ophthalmoscopes are available and continuously being developed, adding the smartphone may not necessarily make a device better. The applications using the smartphone on the portable fundus camera may be dependent on the availability and the need for particular functionalities.

Table 3 Comparison of fundus imaging systems

\begin{tabular}{lllll}
\hline & $\begin{array}{l}\text { Direct } \\
\text { Ophthalmoscope }\end{array}$ & $\begin{array}{l}\text { PanOptic iExaminer } \\
\text { System }\end{array}$ & $\begin{array}{l}\text { Traditional Fundus Camera } \\
\text { (Topcon TRC-NW8F) }\end{array}$ & $\begin{array}{l}\text { Ultrawide field SLO } \\
\text { (Optos California af) }\end{array}$ \\
\hline Field of View & $5^{\circ}$ & $25^{\circ}-30^{\circ}$ & $45^{\circ}$ & $200^{\circ}$ \\
Resolution & N/A & $720 \times 1280$ pixel & 16.2 megapixel & $14 \mu \mathrm{um}$ \\
Portability & Yes & Yes & No & No \\
Cost & Low & Low & High & Very High \\
Smart Phone Adapted & No & Yes & No & No \\
Availability for Screening & Yes & Yes & No & No \\
\hline
\end{tabular}




\section{Conclusions}

This study demonstrated the feasibility of characterizing retinal vasculature using the PanOptic iExaminer System, which yielded sufficient image quality of the fundus photos for quantitative analysis of $\mathrm{A} / \mathrm{V}$ ratio and vessel density. The device appears to provide the benefit of portability, easy data transferring, and cost-effectiveness for the possible use in pre-clinical screening of systemic, cerebral, and ocular diseases.

\section{Acknowledgments}

Not applicable.

\section{Authors' contributions}

$H H, H W, M X, \sqcup, H W$, and JW collected, analyzed, and interpreted the data. $\mathrm{HH}, \mathrm{HJ}, \mathrm{TR}$, and JW were the major contributors for drafting the manuscript. All authors read and approved the final manuscript.

\section{Funding}

The work has been supported by NIH Center Grant P30 EY014801, NINDS 1R01NS111115-01 (Wang), the Ed and Ethel Moor Alzheimer's Disease Research Program (Florida Health, 20A05, to Jiang) and a grant from Research to Prevent Blindness (RPB). Visiting scholar activities (Haicheng Wei and Mingxia Xiao) were supported by the North Minzu University Scientific Research Projects (Major projects No. 2019KJ37 and 2018XYZDX11), National Natural Science Foundation of China (No. 61861001) and Natural Science Foundation of Ningxia (No. 2020AAC03220).

\section{Availability of data and materials}

The datasets used and analyzed for the present study are available from the corresponding author upon reasonable request.

\section{Ethics approval and consent to participate}

All research methods were conducted following the tenets of the declaration of Helsinki and approved by the ethics committee board of the University of Miami (ID 20070492). All subjects were recruited voluntarily and were informed about the purposes, methods, and the potential risks of the study. A signed consent form was obtained from each volunteer.

\section{Consent for publication}

All study subjects gave informed consent.

\section{Competing interests}

The authors declare that they have no competing interests.

\section{Author details}

${ }^{1}$ Shenzhen Key Laboratory of Ophthalmology, Shenzhen Eye Hospital, Jinan University, Shenzhen, China. ${ }^{2}$ Department of Ophthalmology, Bascom Palmer Eye Institute, University of Miami Miller School of Medicine, 1638 NW 10th Avenue, McKnight Building - Room 202A, Miami, FL 33136, USA. ${ }^{3}$ Department of Electrical and Computer Engineering, Florida International University, Miami, FL, USA. ${ }^{4}$ School of Electrical and Information Engineering, North Minzu University, Yinchuan, Ningxia, China. ${ }^{5}$ Eye hospital, China Academy of Chinese Medical Sciences, Beijing, China. ${ }^{6}$ Department of Neurology, University of Miami Miller School of Medicine, Miami, FL, USA.

Received: 14 October 2019 Accepted: 17 August 2020

Published online: 08 September 2020

\section{References}

1. Patton N, Aslam T, Macgillivray T, Pattie A, Deary IJ, Dhillon B. Retinal vascular image analysis as a potential screening tool for cerebrovascular disease: a rationale based on homology between cerebral and retinal microvasculatures. J Anat. 2005:206(4):319-48.

2. Stevenson $\mathrm{CH}$, Hong SC, Ogbuehi KC. Development of an artificial intelligence system to classify pathology and clinical features on retinal fundus images. Clin Exp Ophthalmol. 2019;47(4):484-9.
3. Doubal FN, MacGillivray TJ, Patton N, Dhillon B, Dennis MS, Wardlaw JM Fractal analysis of retinal vessels suggests that a distinct vasculopathy causes lacunar stroke. Neurology. 2010;74(14):1102-7.

4. Arnould L, Binquet C, Guenancia C, Alassane S, Kawasaki R, Daien V, et al. Association between the retinal vascular network with Singapore "I" Vessel Assessment (SIVA) software, cardiovascular history and risk factors in the elderly: the Montrachet study, population-based study. PLoS One. 2018; 13(4):e0194694

5. Schrijvers EM, Buitendijk GH, Ikram MK, Koudstaal PJ, Hofman A, Vingerling $J R$, et al. Retinopathy and risk of dementia: the Rotterdam Study. Neurology. 2012;79(4):365-70

6. Panwar N, Huang P, Lee J, Keane PA, Chuan TS, Richhariya A, et al. Fundus photography in the 21 st century--a review of recent technological advances and their implications for worldwide healthcare. Telemed J E Health. 2016; 22(3):198-208

7. Gill JM, Cole DM, Lebowitz HM, Diamond JJ. Accuracy of screening for diabetic retinopathy by family physicians. Ann Fam Med. 2004;2(3):218-20

8. McComiskie JE, Greer RM, Gole GA. Panoptic versus conventional ophthalmoscope. Clin Exp Ophthalmol. 2004;32(3):238-42.

9. Tan A, Mallika P, Aziz S, Asokumaran T, Intan G, Faridah H. Comparison between the panoptic ophthalmoscope and the conventional direct ophthalmoscope in the detection of sight threatening diabetic retinopathy: the Kuching diabetic eye study. Malays Fam Physician. 2010;5(2):83-90.

10. Hubbard LD, Brothers RJ, King WN, Clegg LX, Klein R, Cooper LS, et al. Methods for evaluation of retinal microvascular abnormalities associated with hypertension/sclerosis in the atherosclerosis risk in communities study. Ophthalmology. 1999;106(12):2269-80.

11. Knudtson MD, Lee KE, Hubbard LD, Wong TY, Klein R, Klein BE. Revised formulas for summarizing retinal vessel diameters. Curr Eye Res. 2003;27(3): 143-9.

12. Setiawan A, Mengko T, Santoso O, Suksmono A. Color Retinal Image Enhancement using CLAHE. In: International Conference on ICT for Smart Society: IEEE; 2013. p. 1-3.

13. Luo $L$, Chen $D$, Xue D. Retinal blood vessels semantic segmentation method based on modified U-Net. In: 2018 Chinese Control And Decision Conference (CCDC): IEEE; 2018.

14. Wang C, Zhao Z, Ren Q, Xu O, Yu Y. Dense U-net based on patch-based learning for retinal vessel segmentation. Entropy. 2019:21(2):168.

15. Ronneberger O, Fischer P, Brox T. U-Net: convolutional networks for biomedical image segmentation. In: International Conference on Medical Image Computing and Computer-Assisted Intervention: Springer; 2015. p. 234-41.

16. Wang X, Zhangwei J, Wen X, Zhenyan J, Gu H, Li W, Miao B, Jing H. Retina Blood vessel segmentation using a U-Net based convolutional neural network. In: International Conference on Data Science; 2018.

17. Staal J, Abràmoff MD, Niemeijer M, Viergever MA, van Ginneken B. Ridgebased vessel segmentation in color images of the retina. IEEE Trans Med Imaging. 2004;23(4):501-9.

18. Wadhwani M, Vashist P, Singh SS, Gupta N, Malhotra S, Gupta A, et al Diabetic retinopathy screening programme utilising non-mydriatic fundus imaging in slum populations of New Delhi, India. Tropical Med Int Health. 2018;23(4):405-14

19. Gosheva M, Klameth C, Norrenberg L, Clin L, Dietter J, Haq W, et al. Quality and learning curve of handheld versus stand-alone non-mydriatic cameras. Clin Ophthalmol. 2017;11:1601-6.

20. Xu X, Ding W, Wang X, Cao R, Zhang M, Lv P, et al. Smartphone-based accurate analysis of retinal vasculature towards point-of-care diagnostics. Sci Rep. 2016;6:34603.

21. Xu X, Wang R, Lv P, Gao B, Li C, Tian Z, et al. Simultaneous arteriole and venule segmentation with domain-specific loss function on a new public database. Biomed Opt Express. 2018:9(7):3153-66.

22. Patel M, Mukherjee D, Farsiu S, Munoz B, Blood AB, Wilson CG, et al. Estimation of gestational age via image analysis of anterior lens capsule vascularity in preterm infants: a pilot study. Front Pediatr. 2019;7:43.

23. Day LM, Wang SX, Huang CJ. Nonmydriatic fundoscopic imaging using the Pan Optic iExaminer system in the pediatric emergency department. Acad Emerg Med. 2017;24(5):587-94

24. Petrushkin H, Barsam A, Mavrakakis M, Parfitt A, Jaye P. Optic disc assessment in the emergency department: a comparative study between the PanOptic and direct ophthalmoscopes. Emerg Med J. 2012;29(12):1007-8 
25. Desai AD, Peng C, Fang L, Mukherjee D, Yeung A, Jaffe SJ, et al. Opensource, machine and deep learning-based automated algorithm for gestational age estimation through smartphone lens imaging. Biomed Opt Express. 2018:9(12):6038-52.

26. Lee JY, Gallo RA, Alabiad CR. Evaluating the effectiveness of small-group training in teaching medical students integral clinical eye examination skills. J Acad Ophthalmol. 2020;12(1):e79-86.

27. Besenczi R, Szitha K, Harangi B, Csutak A, Hajdu A. Automatic optic disc and optic cup detection in retinal images acquired by mobile phone. In: 9th International Symposium on Image and Signal Processing and Analysis (ISPA 2015); 2015. p. 139-8.

28. Nghiem AZ, Nderitu P, Lukic M, Khatun M, Largan R, Kortuem K, et al. Comparing diabetic retinopathy lesions in scanning laser ophthalmoscopy and colour fundus photography. Acta Ophthalmol. 2019;97(8):e1035-40.

29. Ponto KA, Werner DJ, Wiedemer L, Laubert-Reh D, Schuster AK, Nickels S, et al. Retinal vessel metrics: normative data and their use in systemic hypertension: results from the Gutenberg health study. J Hypertens. 2017; 35(8):1635-45

30. Ikram MK, de Jong FJ, Vingerling JR, Witteman JC, Hofman A, Breteler MM, et al. Are retinal arteriolar or venular diameters associated with markers for cardiovascular disorders? The Rotterdam study. Invest Ophthalmol Vis Sci. 2004:45(7):2129-34.

31. McClelland JF, O'Donoghue L, McIntyre M, Saunders KJ. Cup-to-disc and arteriole-to-venule ratios in children aged 6-7 and 12-13 years. Ophthalmic Physiol Opt. 2012;32(1):31-8.

32. Mitchell P, Wang JJ, Wong TY, Smith W, Klein R, Leeder SR. Retinal microvascular signs and risk of stroke and stroke mortality. Neurology. 2005; 65(7):1005-9.

33. Wong TY, Cheung N, Islam FM, Klein R, Criqui MH, Cotch MF, et al. Relation of retinopathy to coronary artery calcification: the multi-ethnic study of atherosclerosis. Am J Epidemiol. 2008;167(1):51-8.

34. Bulut M, Kurtuluş F, Gözkaya O, Erol MK, Cengiz A, Akidan M, et al. Evaluation of optical coherence tomography angiographic findings in Alzheimer's type dementia. Br J Ophthalmol. 2018;102(2):233-7.

35. Bursztyn L, Woodward MA, Cornblath WT, Grabe HM, Trobe JD, Niziol L, et al. Accuracy and reliability of a handheld, nonmydriatic fundus camera for the remote detection of optic disc edema. Telemed J E Health. 2018: 24(5):344-50.

Ready to submit your research? Choose BMC and benefit from:

- fast, convenient online submission

- thorough peer review by experienced researchers in your field

- rapid publication on acceptance

- support for research data, including large and complex data types

- gold Open Access which fosters wider collaboration and increased citations

- maximum visibility for your research: over $100 \mathrm{M}$ website views per year

At $\mathrm{BMC}$, research is always in progress.

Learn more biomedcentral.com/submissions 